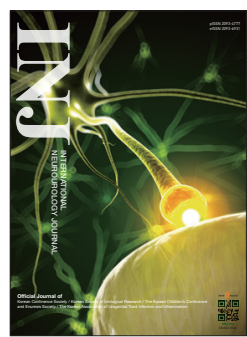

\title{
Origin of Urgency Symptom in Underactive Bladder: Commentary on "Underactive Bladder: Clinical Features, Urodynamic Parameters, and Treatment" (Int Neurourol J 2015;19:185-9)
}

\author{
Dae Kyung Kim \\ Department of Urology, Eulji University School of Medicine, Daejeon, Korea
}

To the editor:

In the previous issue of International Neurourology Journal, $\mathrm{Na}$ than Hoag and Johan Gani reported clinical features of underactive bladder (UAB) in their cohort [1]. The most common urinary symptom among identified $\mathrm{UAB}$ patients was urgency (63.3\%), followed by weak stream (61.0\%). Discussing this unexpected finding, the authors only commented that "an appropriate symptom-based definition will prove challenging to describe" for defining UAB.

Urinary urgency is definitely the predominant symptom of overactive bladder. Of course, a patient with urgency does not always have overactive bladder. As the authors reported, it is quite possible that a patient with urgency will prove to have UAB in actual practice. The origin of urgency symptoms in $\mathrm{UAB}$ patients may be attributed to three possible explanations.

The first candidate is definitely concomitant detrusor overactivity. This condition is traditionally termed detrusor hyperreflexia with impaired contractility (DHIC). DHIC seems to be the most probable and attractive explanation for urgency in UAB. However, only $24.1 \%$ of patients in the cohort proved to have DHIC, which could not explain all cases.

As the next candidate, urinary tract infection (UTI) could be associated with urgency in UAB patients. Recurrent UTI was reported in $25.3 \%$ of patients in the cohort, which possibly affected reports of subjective urinary symptoms. Bacteriuria proved to be associated with urinary urgency, especially in elderly women [2].
The last candidate may be deranged bladder sensation, which is often combined with UAB [3]. In patients with diabetes, a sensory deficit precedes bladder motor problems in the development of UAB [4]. These patients often recognize bladder fullness as a vague pressure in the lower abdomen rather than a true initial voiding sensation. With the resulting increased bladder volume, this recognition tends to come too late to allow enough time for actual voiding. The short time interval between first recognition and actual voiding may cause patients to report urgency symptoms.

Urgency symptoms in UAB may well occur, and originate from diverse causes including DHIC, UTI, or a sensory deficit. The old axiom that "the bladder is an unreliable witness" seems to be also true in the case of UAB [5]. Differential diagnosis may give us a clue to management. In cases of urgency associated with UTI, antibiotics should be considered first. Anticholinergics may be helpful to decrease urgency with DHIC, but not with a sensory deficit. The clinical implication of UAB subclassification by sensory component warrants further research.

- Conflict of Interest: No potential conflict of interest relevant to this article was reported.

\section{REFERENCES}

1. Hoag N, Gani J. Underactive bladder: clinical features, urodynamic
Corresponding author: Dae Kyung Kim (D) http://orcid.org/0000-0002-5709-3768 Department of Urology, Eulji University Hospital, 95 Dunsanseo-ro, Seo-gu, Daejeon 35233, Korea

E-mail: dkkim@eulji.ac.kr / Tel: +82-42-611-3529 / Fax: +82-42-611-3538 Submitted: December 11, 2015 / Accepted after revision: December 11, 2015 (c) (i) (2) This is an Open Access article distributed under the terms of the Creative Commons Attribution Non-Commercial License (http://creativenses/by-nc/3.0/) which permits unrestricted non-commercial use, distribution, and reproduction in any medium, provided the original work is properly cited. 
parameters, and treatment. Int Neurourol J 2015;19:185-9.

2. Brubaker L, Nager CW, Richter HE, Visco A, Nygaard I, Barber $\mathrm{MD}$, et al. Urinary bacteria in adult women with urgency urinary incontinence. Int Urogynecol J 2014;25:1179-84.

3. Osman NI, Chapple CR, Abrams P, Dmochowski R, Haab F, Nitti V, et al. Detrusor underactivity and the underactive bladder: a new clinical entity? A review of current terminology, definitions, epide- miology, aetiology, and diagnosis. Eur Urol 2014;65:389-98.

4. Bansal R, Agarwal MM, Modi M, Mandal AK, Singh SK. Urodynamic profile of diabetic patients with lower urinary tract symptoms: association of diabetic cystopathy with autonomic and peripheral neuropathy. Urology 2011;77:699-705.

5. Blaivas JG. The bladder is an unreliable witness. Neurourol Urodyn 1996;15:443-5. 